\title{
Surface modification of aluminum by runaway electron preionized diffuse discharges in different gases at atmospheric pressure
}

\author{
Mikhail V. Erofeev ${ }^{1,2}$, Mikhail A. Shulepov ${ }^{1}$, Victor F. Tarasenko ${ }^{1,2^{*}}$ \\ ${ }^{1}$ Institute of High Current Electronics, SB, RAS, 634055, 2/3 Akademichesky Ave., Tomsk, Russia; \\ ${ }^{2}$ National Research Tomsk Polytechnic University, 634050, 30 Lenin Ave., Tomsk, Russia
}

\begin{abstract}
The paper presents the results of an examination of aluminum samples exposed to runaway electron preionized diffuse discharges in air, nitrogen, and argon at atmospheric pressure. The changes in the chemical composition, structure, and hardness of the aluminum surface layers caused by the action of the discharge were investigated. It has been found that the oxygen and carbon concentrations in the surface layers depend on the number of discharge pulses and on the chemical composition of the working gas. The goal of the study was to find possible uses of runaway electron preionized diffuse discharges in research and industry.
\end{abstract}

Keywords: Runaway electron preionized diffuse discharge, REP DD, surface modification, aluminum

\section{INTRODUCTION}

Various methods of surface modification of materials by electrical discharges aimed at giving the surface layers new properties have been efficiently used for a long time. However, these methods are based on electrolysis and, therefore, have a major drawback. They are not safe for the environment and personnel, as electrolytes are usually complex mixtures of salts and acids having high temperatures during the process of electrolysis.

In this regard, the surface modification of materials as a result of plasma chemical reactions is of great interest. The research in this area has been under way for a rather long time, and the results have already been used in developing various surface treatment technologies. In particular, studies on nitriding of titanium surfaces [1-3] or on deposition of energy saving coatings on glass surfaces [4] can be mentioned. All of these studies and the development of various surface modification techniques are aimed at generating new surface properties of materials not characteristic of them in normal state.

Since 2003, we have studied a new type of volumetric discharges in gases, namely, the runaway electron preionized diffuse discharge (REP DD) [5-7]. This discharge is volumetric at high pressures and does not require preionization of the gas to be initiated. The results of our studies of REP DDs gave us impetus to begin investigations of the surface properties of different materials exposed to this type of discharge [6-11].

\section{EXPERIMENTAL EQUIPMENT AND PROCEDURE}

The experiments on studying the action of an REP DD on aluminum were carried out on two setups. The first one was based on a RADAN-220 generator [12], which produced voltage pulses of amplitude $360 \mathrm{kV}$ (open circuit voltage), FWHM $\sim 0.7 \mathrm{~ns}$ (across a matched load), and rise time $\sim 0.5 \mathrm{~ns}$. Measurements have shown that the discharge peak current was $\sim 3 \mathrm{kA}$ and the total duration of the discharge current pulse was $\sim 13 \mathrm{~ns}$ (the duration of the first half period of the discharge current was $\sim 3 \mathrm{~ns}$ ). The samples were irradiated in a repetitive pulse mode at a pulse repetition frequency of $1 \mathrm{~Hz}$. The specific power input to the discharge plasma was over $100 \mathrm{MW} / \mathrm{cm}^{3}$. A tube of diameter $6 \mathrm{~mm}$ made of $50 \mu \mathrm{m}$ thick titanium foil was used as a cathode. In this setup, specially prepared aluminum plates of thickness $1.5 \mathrm{~mm}$ were used for the anode. The electrode gap spacing was $18 \mathrm{~mm}$. The experiment using the RADAN-220 setup was performed in an open chamber, with free access of air.

*VFT@1oi.hcei.tsc.ru; phone 83822 491-685; fax 83822 492-410; www.hcei.tsc.ru

International Conference on Atomic and Molecular Pulsed Lasers XII, edited by Victor F. Tarasenko,

Andrey M. Kabanov, Proc. of SPIE Vol. 9810, 98100V · (c) 2015 SPIE

CCC code: $0277-786 \mathrm{X} / 15 / \$ 18 \cdot$ doi: $10.1117 / 12.2224705$ 
The other experiment was carried out with nitrogen and argon at atmospheric pressure. In this case, the NPG-15/2000N generator capable of producing voltage pulses of amplitude up to $30 \mathrm{kV}$, FWHM $6 \mathrm{~ns}$, and discharge current up to $100 \mathrm{~A}$ was used as a high voltage source [13]. With this generator, the specific power input to the discharge plasma was $\sim 10 \mathrm{MW} / \mathrm{cm}^{3}$. Plates of thickness $1 \mathrm{~mm}$ and foils of thickness $200 \mu \mathrm{m}$ were used for the anode. Irradiation was carried out in a repetitive pulse mode at a frequency of $2 \mathrm{kHz}$ in a stream of nitrogen or argon at a flow rate of $5 \mathrm{sl} / \mathrm{min}$.

In this experiment, an evacuated chamber was used through which the gas required for a particular experiment was pumped. In all cases, the gas pressure corresponded to the atmospheric pressure. Each sample was prepared by polishing followed by rinsing with distilled water and alcohol in an ultrasonic bath. After wiping, the sample was placed in the discharge chamber where it was treated with a diffuse discharge (Fig. 1).
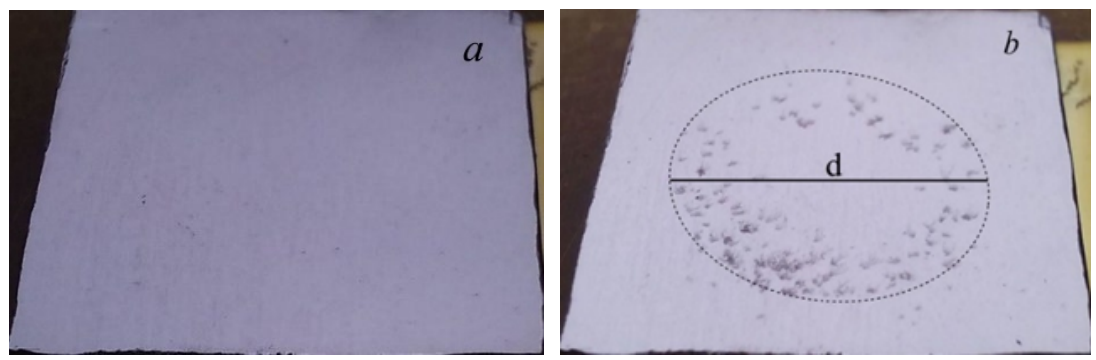

Figure 1. Aluminum sample: as-prepared (a) and exposed in air to 6000 discharge pulses generated by the RADAN -220 (b).

The diameter of the discharge-affected region $\mathrm{d}$ was $\sim 25 \mathrm{~mm}$.

After REP DD treatment, the samples were placed, to prevent the influence of air, in a capsule filled with an inert gas (argon) and passed for Auger spectroscopy to examine the elemental composition of their surface layers. The examination was performed with the use of a Shtil-2 Auger spectrometer [14].

\section{EXPERIMENTAL RESULTS}

\subsection{Surface modification by REP DD in air}

The results of examination of the elemental composition of the surface layers of aluminum irradiated in air using the RADAN-220 generator are presented in Fig. 2.

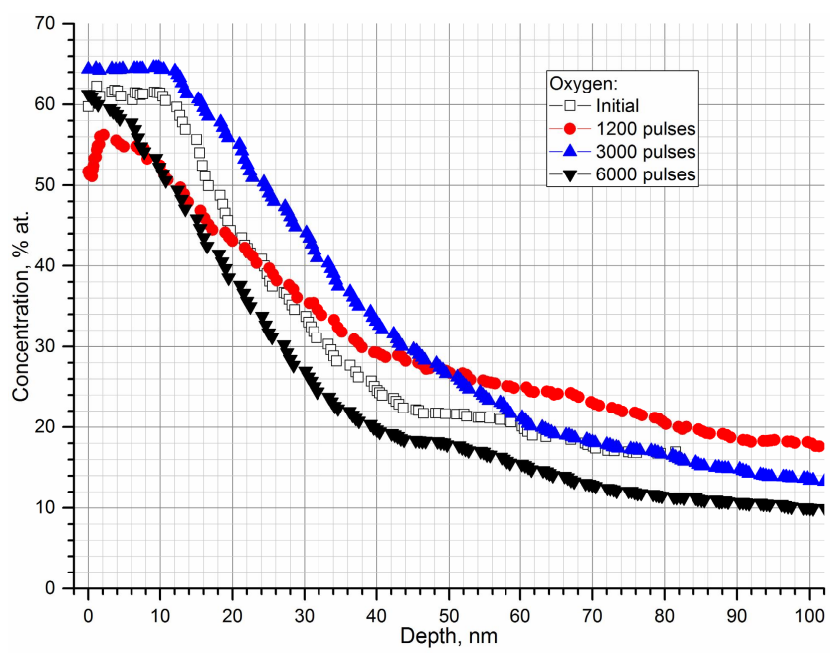

Figure 2. Oxygen concentration in the surface layers of aluminum versus irradiation dose.

It can be seen that the oxygen concentration in the treated aluminum samples is slightly different from that in the asprepared samples.

The results of examination of the carbon concentration for the same samples are given in Fig. 3. 


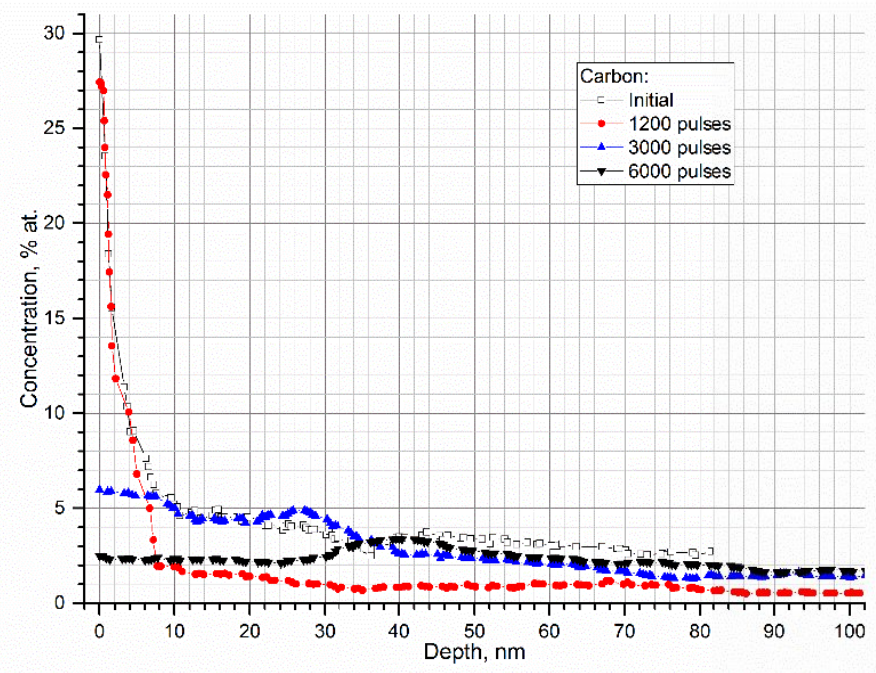

Figure 3. Carbon concentration in the surface layers of aluminum versus irradiation dose.

It can be seen that the high irradiation doses played a prominent part in the surface cleaning of aluminum. On exposure to 1200 pulses, the carbon concentration remained unchanged through the first $5 \mathrm{~nm}$ of the surface layer, but in the deeper layers, it decreased from $5 \%$ to $1 \%$. Increasing the irradiation dose decreased the carbon concentration at the surface from $30 \%$ to $6 \%$ and $2 \%$ for 3000 and 6000 pulses, respectively.

\subsection{Surface modification by REP DD in nitrogen and argon}

To irradiate the samples in nitrogen and argon, we used the system allowing surface treatment in a repetitive pulse mode. The irradiated samples were passed for elemental analysis. At the time of the experiment, we had at our disposal samples of materials produced in Russia, China, and France.

The China produced aluminum samples turned out to respond to the REP DD irradiation most readily (Fig. 4).

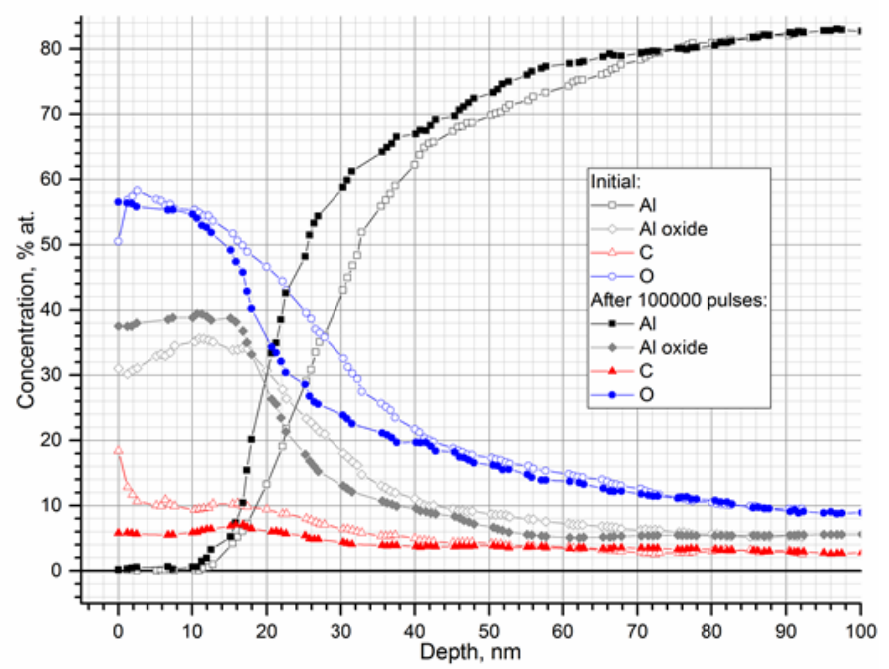

Figure 4. Concentrations of the main elements in samples of China produced aluminum before and after treatment with 100000 discharge pulses in nitrogen.

As a result of the REP DD treatment of the samples, carbon-containing compounds were removed from the surface layer and oxygen was removed from somewhat deeper layers $(15-40 \mathrm{~nm})$ adjacent to the metal bulk. The aluminum oxide concentration increased a little at the surface and decreased at the bulk boundary.

The response of the samples of Russia produced aluminum to the diffuse discharge treatment was different (Fig. 5). 


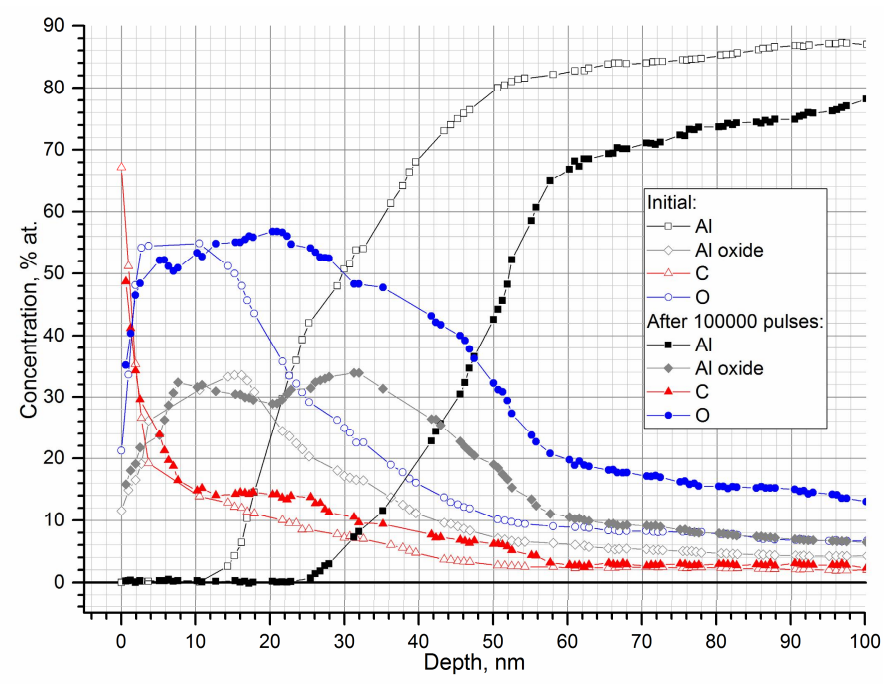

Figure 5. Concentrations of the main elements in samples of Russia produced aluminum before and after treatment with 100000 discharge pulses in nitrogen.

It can be seen that as-supplied Russia produced aluminum was in fact similar to that produced in China, except for the greater carbon content within the first $20 \mathrm{~nm}$ depth of the surface layer. However, the oxygen and aluminum oxide contents in the Russian aluminum samples were lower (by about 5\%) compared to the Chinese samples.

However, when exposed to REP DD with the same dose and under the same conditions, the Russia produced aluminum responded quite differently. The carbon compounds remained almost intact in the surface layer, whereas the oxygen and aluminum oxide concentrations increased beginning from the $10 \mathrm{~nm}$ depth, and oxygen penetrated throughout the examined depth of the metal bulk.

We intentionally tried to choose aluminum samples different from each other and so used plates and foils produced in different countries. The French aluminum sample (see Fig. 6) was strongly different in surface condition from those produced in Russia and China. It seems that the surface of the French sample was even more porous than that of the Russian sample. The surface of the as-supplied sample was oxidized to a greater extent and to deeper layers (up to $50 \mathrm{~nm})$.

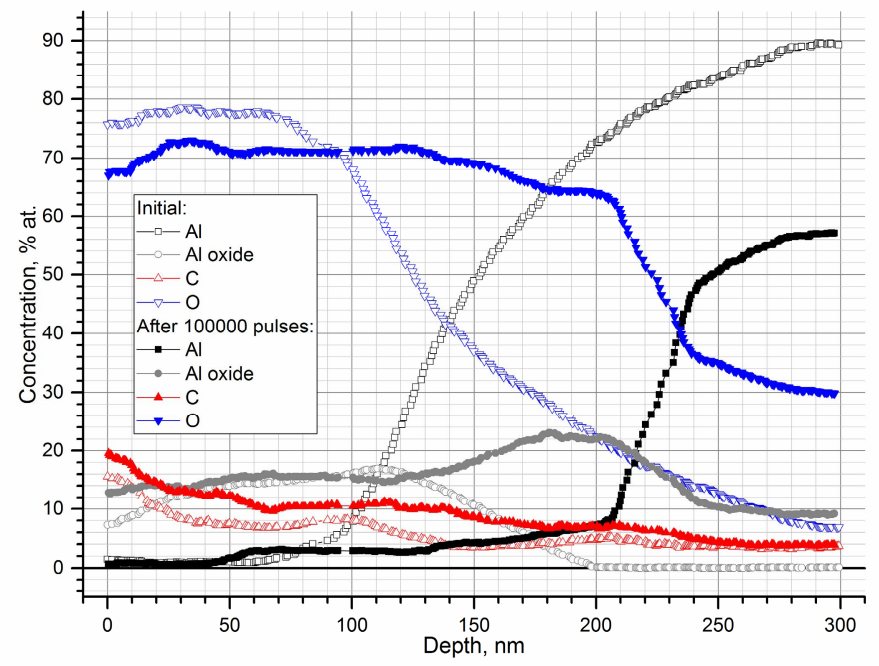

Figure 6. Concentrations of the main elements in samples of France produced aluminum before and after treatment with 100000 discharge pulses in nitrogen. 
It consisted of hydrocarbon compounds, oxygen, and aluminum oxide. The oxygen concentration in the French sample decreased to $10 \%$ at a depth of $270 \mathrm{~nm}$ against 50 and $80 \mathrm{~nm}$ in the Russian and the Chinese sample, respectively. The same trend was observed for carbon: its $10 \%$ at. concentration in the Russian and Chinese samples was reached at a depth of $20 \mathrm{~nm}$, whereas in the French sample, this carbon concentration was observed only at a depth of $150 \mathrm{~nm}$.

Nevertheless, despite the highly contaminated surface of the French sample, the changes in main element concentrations resulted from the exposure to REP DD in nitrogen showed the same trend as observed for the Russian sample. The carbon concentration remained almost unchanged, whereas the oxygen concentration increased dramatically and reached over $60 \%$ at. a depth of $210 \mathrm{~nm}$. The changes in aluminum oxide concentration were also similar to its changes in the Russian sample. In the deep layers, the aluminum oxide concentration was over $20 \%$ at., whereas its changes, compared to the as-supplied sample, were within the measurement error.

The results obtained indicate that the surface of the French sample was highly porous. In addition, the high oxygen content in the as-supplied material suggests that the sample was exposed to air for a longer time than the other samples.

Analysis of the results of the REP DD action on aluminum in nitrogen provokes the question of why the metal is oxidized under these conditions. According to the certified data for the nitrogen used in the experiments, the volume fraction of oxygen in molecular form and as a water vapor component made no more than $0.0017 \%$. We suppose that during the discharge operation, oxygen ions are produced which interact with nitrogen and water to form nitrogen oxides and more complex compounds, such as molecular nitric acids [16]. Along with this, some of the negative oxygen ions penetrate, under the action of the accelerating voltage, into the anode surface layer and oxidize the metal (aluminum in the case under consideration).

After the exposure of the samples to REP DD with the same dose (100000 pulses) in argon at normal pressure, no changes in their surfaces were detected visually. Therefore, in this case, the elemental composition of the sample surface layers was not analyzed.

\section{CONCLUSIONS}

Based on the obtained data on the action of REP DDs on aluminum surfaces, it has been found that the test samples showed two main responses to this type of treatment: oxidation and freeing of carbon. Supposedly, the degree of response primarily depends on the porosity of the metal rather than on the composition of the working gas. The more porous the surface of an aluminum sample, the deeper the oxygen penetration and the more problematic the removal of the carbon compounds present in the surface layers of as-supplied samples.

\section{ACKNOWLEDGMENTS}

The work is performed in the framework of the Russian Science Foundation (Project No. 14-29-00052).

\section{REFERENCES}

[1] Liner, V. I., [The protective coating of metals], Metallurgy, Moscow, 558 (1974).

[2] Koval', N. N., Gromov, V. E., [Modern Trends in Modification of Materials Structure and Properties], NTL, Tomsk, 380 (2015).

[3] Averyanov, E. E., [Reference anodizing], Mechanical engineering, Moscow, 224 (1988).

[4] Ladyzhensky, O. B., Zaslavsky, V. M., Kovsharov, N. F., Rasputin, R. M., Sochugov, N. S., "Ion beam treatment of glass surfaces as a method for increased metal film adhesion," Laser Part. Beams, 21(2), 291-293 (2003).

[5] Tarasenko, V. F., Orlovskii, V. M., Shunailov, S. A., "Forming of an electron beam and a volume discharge in air at atmospheric pressure," Russ. Phys. J., 46(3), 325-327 (2003).

[6] Baksht, E. Kh., $\quad$ Burachenko, A. G., $\quad$ Kostyrya, I. D., $\quad$ Lomaev, M. I., $\quad$ Rybka, D. V., $\quad$ Shulepov, M. A., Tarasenko, V. F., "Runaway-electron-preionized diffuse discharge at atmospheric pressure and its application," J. Phys. D. Appl. Phys., 42(18), 185201 (2009).

[7] Tarasenko, V.F., [Runaway Electrons Preionized Diffuse Discharges], Nova Science Publishers Inc., New York, 598 (2014). 
[8] Shulepov, M. A., Tarasenko, V. F., Goncharenko, I. M., Koval', N. N., Kostyrya, I. D., "Modification of the near-surface layers of a copper foil under the action of a volume gas discharge in air at atmospheric pressure," Tech. Phys. Lett., 34(4), 296-299 (2008).

[9] Shulepov, M. A., Akhmadeev, Y. K., Tarasenko, V. F., Kolubaeva, Y., A. Krysina, O. V. and Kostyrya, I. D., "Modification of surface layers of copper under the action of the volumetric discharge initiated by an avalanche electron beam in nitrogen and CO2 at atmospheric pressure," Russ. Phys. J., 53(12), 1290-1294 (2011).

[10] Voitsekhovskii, A. V., Grigor'ev, D. V., Korotaev, A. G., Kokhanenko, A. P., $\quad$ Tarasenko, V. F., Shulepov, M. A., "A change in the electro-physical properties of narrow-band CdHgTe solid solutions acted upon by a volume discharge induced by an avalanche electron beam in the air at atmospheric pressure," Russ. Phys. J., 54(10), 1152-1155 (2012).

[11] Shulepov, M. A., Erofeev, M. V., Ivanov, Y. F., Oskomov, K. V., Tarasenko, V. F., "Action of runaway electron preionized diffuse discharge on steel: composition, structure, and properties," J. Phys. Sci. Appl., 15, 33-37 2015.

[12] Yalandin, M. I. and Shpak, V. G., "Compact high-power subnanosecond repetitive-pulse generators," Instrum. Exp. Tech., 44(3), 285-310 (2001).

[13] Lyublinsky, A. G., Korotkov, S. V., Aristov, Y. V., Korotkov, D. A., "Pulse power nanosecond-range DSRDbased generators for electric discharge technologies," IEEE Trans. Plasma Sci., 41(10), 2625-2629 (2013).

[14] Shulepov, I. A., [Development and application of combined atomic and nuclear physics methods for examining modified layers of materials], PhD thesis, Tomsk, 141 (2004).

[15]"The mechanism of formation of anodic oxide films," Metal Central portal of the Russian Federation, http://metallicheckiy-portal.ru/articles/zashita_ot_korrozii_metalla/aluminii/zashita_alyminia_pokritiami/2 (7 October 2015).

[16] Rusin, A. A., Batalova, V. N., Sosnin, E. A., Shulepov, M. A., "Photochemical air ozonizer," Proc. VIII AllRussian Conference School "Innovation 2012", 1, 137-140 (2012). 